Provided for non-commercial research and education use. Not for reproduction, distribution or commercial use.

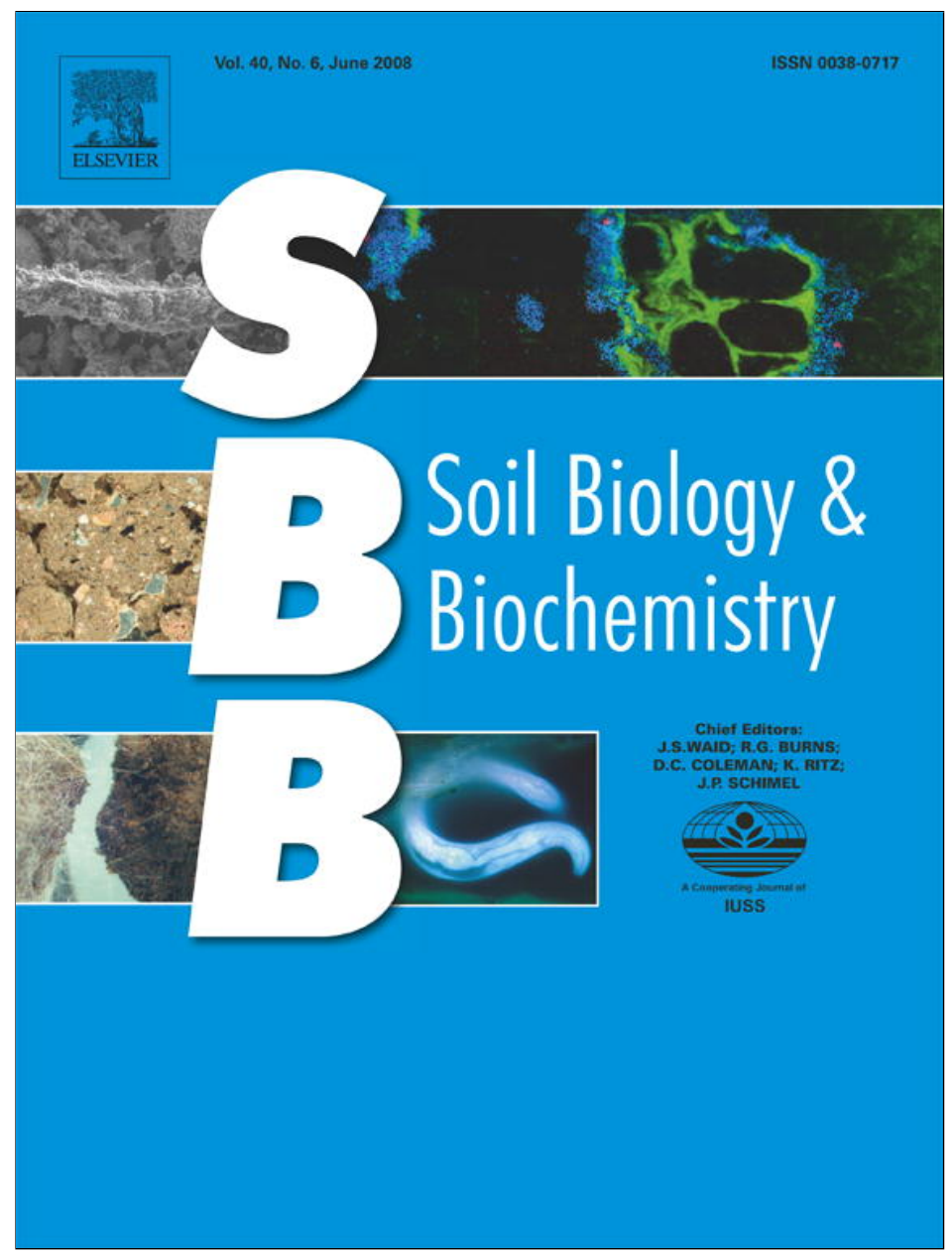

This article appeared in a journal published by Elsevier. The attached copy is furnished to the author for internal non-commercial research and education use, including for instruction at the authors institution and sharing with colleagues.

Other uses, including reproduction and distribution, or selling or licensing copies, or posting to personal, institutional or third party websites are prohibited.

In most cases authors are permitted to post their version of the article (e.g. in Word or Tex form) to their personal website or institutional repository. Authors requiring further information regarding Elsevier's archiving and manuscript policies are encouraged to visit:

http://www.elsevier.com/copyright 


\title{
Challenges in modelling dissolved organic matter dynamics in agricultural soil using DAISY
}

\author{
Birgitte Gjettermann ${ }^{\mathrm{a}, *}$, Merete Styczen ${ }^{\mathrm{b}}$, Hans Christian B. Hansen ${ }^{\mathrm{c}}$, \\ Finn P. Vinther ${ }^{\mathrm{d}}$, Søren Hansen ${ }^{\mathrm{a}}$ \\ ${ }^{a}$ Faculty of Life Sciences, Department of Agricultural Sciences, University of Copenhagen, Højbakkegaird Allé 9, DK-2630 Taastrup, Denmark \\ ${ }^{\mathrm{b}}$ DHI-Water and Environment, Department of Hydrology, Soil and Waste, Denmark \\ ${ }^{\mathrm{c}}$ Faculty of Life Sciences, Department of Natural Sciences, University of Copenhagen, Denmark \\ ${ }^{\mathrm{d}}$ Faculty of Agricultural Sciences, Institute of Agroecology and Environment, University of Aarhus, Denmark
}

Received 10 July 2007; received in revised form 20 November 2007; accepted 7 January 2008

Available online 20 February 2008

\begin{abstract}
Because dissolved organic matter (DOM) plays an important role is terrestrial C-, N- and P-balances and transport of these three components to aquatic environments, there is a need to include it in models. This paper presents the concept of the newly developed DOM modules implemented in the DAISY model with focus on the quantification of DOM sorption/desorption and microbial-driven DOM turnover. The kinetics of DOM sorption/desorption is described by the deviation of the actual DOM concentration in solution from the equilibrium concentration, $C_{\mathrm{eq}}$. The $C_{\mathrm{eq}}$ is soil specific and estimated from pedotransfer functions taking into account the soil content of organic matter, $\mathrm{Al}$ and Fe oxides. The turnover of several organic matter pools including one DOM pool are described by first-order kinetics.

The DOM module was tested at field scale for three soil treatments applied after cultivating grass-clover swards. Suction cups were installed at depths 30,60 and $90 \mathrm{~cm}$ and soil solution was sampled for quantification of dissolved organic C (DOC) and dissolved organic $\mathrm{N}$ (DON). In the topsoil, the observed fluctuations in DOC were successfully simulated when the sorption/desorption rate coefficient $k$ was low. In the subsoil, the observed concentrations of DOC were steadier and the best simulations were obtained using a high $k$. The model shows that DOC and DON concentrations are levelled out in the subsoils due to soil buffering. The steady concentration levels were based on the $C_{\text {eq }}$ for each horizon and the kinetic concept for sorption/desorption of DOC appeared a viable approach. If $C_{\text {eq }}$ was successfully estimated by the pedotransfer function it was possible to simulate the DOC concentration in the subsoil. In spite of difficulties in describing the DOC dynamics of the topsoil, the DOM module simulates the subsoil concentration level of DOC well, and also - but with more uncertainty - the DON concentration level.
\end{abstract}

(C) 2008 Elsevier Ltd. All rights reserved.

Keywords: Dissolved organic matter; Dissolved organic C; Dissolved organic N; Initial mass isotherm; Sorption kinetics; Organic matter; Modelling DOM dynamics; Leaching

\section{Introduction}

Dissolved organic matter (DOM) is an important contributor to transport of nutrients in the soil system (Guggenberger and Kaiser, 2003). Export of DOM and associated $\mathrm{N}$ and $\mathrm{P}$ from soils to surface waters may contribute substantially to eutrophication (Stepanauskas

\footnotetext{
${ }^{*}$ Corresponding author. Tel.: +4535332218; fax: +4535333384.

E-mail address: bgj@life.ku.dk (B. Gjettermann).
}

et al., 2002). Dissolved organic carbon (DOC) concentrations in 22 UK upland waters have increased by an average of $91 \%$ during the last 15 years and there is evidence of similar changes at other monitoring sites across Europe and North America. Long-term DOC leaching may have wide-ranging impacts on freshwater biota, drinking water quality, coastal marine ecosystems and upland carbon balances (Evans et al., 2005).

Soil solutions contain varying amounts of DOM, which originates from plant litter, soil humus, microbial biomass, 
and from root exudates (Kalbitz et al., 2000), but the quantitative contribution made by each of these sources is controversial and differs depending on the definition and methods used for determination of DOM (Zsolnay, 1996). Microbial control of DOM production is frequently mentioned in studies of DOM cycling. Hence, Guggenberger et al. (1994) found that the chemical composition of DOM fractions indicated that DOM is mainly comprised of by-products of organic matter mineralization and of products of microbial synthesis. In 14 old agricultural fields that had been abandoned, Zak et al. (1990) observed that water-extractable $\mathrm{C}$ and microbial biomass $\mathrm{C}$ were highly correlated and the water-extractable $\mathrm{C}$ was about $20 \%$ of microbial biomass C. On the contrary, Zsolnay (1996) stated that the largest and most consistent source of DOM presumably is the immobile SOM, which is approximately 100 -fold more abundant than the DOM itself. Findings of ${ }^{14} \mathrm{C}$ studies by Trumbore et al. (1992) and Tegen and Dorr (1996) suggest that mobile DOM is produced from rather old fractions of organic material.

Evidence from studies in soil systems indicates that sorptive protection of DOM may be of particular importance. According to several authors (e.g. Guggenberger and Zech, 1992; Qualls and Haines, 1992; Kaiser et al., 1996) the change in concentration of DOM during transport through the mineral soil is caused by sorption of DOM on to the mineral phase. Iron and aluminium oxides are important sorbents of DOM with sorption usually described as surface complexation of DOM carboxylic acid groups (Kaiser et al., 1997). Additionally, it is often found that soil is able to release DOM when exposed to aqueous solution containing no or very low concentrations of DOM (Nodvin et al., 1986; Kaiser, 2001; Gjettermann et al., 2007). Thus, the soil solid phase may not only sorb DOM but may also release it.

Modelling has become an important tool in studies of soil nutrients, be it nutrient uptake by crops or losses by leaching to the environment. The issue of identifying and particularly quantifying the sources of DOM in soil is rather challenging and different approaches have been developed. In the ANIMO model, described by Groenendijk and Kroes (1999), manure and slurry contains a soluble organic fraction that is added to the DOM pool when applied. Additionally, decomposition of fresh organic material results in production of DOM. On the other hand, microbial production of DOM is the only source of DOM in the CENTURY model (Parton et al., 1994). The DyDOC model (Michalzik et al., 2003, Tipping et al., 2005) and the model described by Neff and Asner (2001) also include physical/chemical sorption of DOM in soil. In the DyDOC model, the DOM sorption is described by an equilibrium partitioning coefficient where the parameterization of the partitioning coefficient accounts for differences in soil $\mathrm{pH}, \mathrm{Al}$ concentration in soil solution, DOC properties and the nature of soil solids (Lofts et al., 2001a, b). In the model described by Neff and Asner (2001) it is assumed that DOM sorption at equilibrium is described by the initial mass-isotherm. If water flow occurs, the isotherm is modified and kinetic considerations are included, by use of a very simple algorithm.

Process descriptions for DOM dynamics were recently included in the DAISY model. The DAISY code (Hansen et al., 1990, 1991; Abrahamsen and Hansen, 2000) has been validated at several occasions (e.g. Shaffer et al., 2001) and has always been evaluated favourable, in particular with regard to simulation of nitrogen and carbon transformations in soil (de Willigen, 1991; Vereecken et al., 1991; Diekkrüger et al., 1995; Smith et al., 1997). This paper presents the concept of the newly developed DOM module in the DAISY model, which was tested with field data from a study on DOM mobilization and transport after cultivating grassclover swards (Vinther et al., 2006). In this model DOM is defined as dissolved organic substances passing through a $0.45 \mu \mathrm{m}$ filter. In the present paper, the effect of soil treatments on the simulated DOM dynamics is investigated with special focus on the importance of DOM sorption/ desorption in relation to microbial-driven DOM turnover.

\section{Materials and methods}

\subsection{Model description}

The mechanistic, deterministic, simulation model DAISY is open software, which simulates water, $\mathrm{C}$ and $\mathrm{N}$ dynamics in the soil-plant-atmosphere system. The model consists of more than 100 submodels for simulating soil-vegetation-atmosphere transfer processes, soil physical processes like soil water and solute movement, and soil temperature; organic matter turnover resulting in mineralization and immobilization of soil solution nitrate and ammonium; crop growth and physiology including different submodels of photosynthesis and radiation distribution in the canopy; along with a detailed system of management operations at field scale. Simulations are performed by combining relevant submodels and setting a number of parameters describing the soil, crop, climatic conditions and management operations. For the processes involved in the simulation, mass balances can be calculated. The source code as well as the original documentation (Hansen et al., 1990) can be downloaded from the homepage (DAISY, 2007). In DAISY, DOM is quantified with respect to $C$ and $\mathrm{N}$, which is referred to as dissolved organic $\mathrm{C}$ (DOC) and dissolved organic $\mathrm{N}(\mathrm{DON})$, respectively. Each horizon defined in the DAISY set-up is parameterized separately according to soil texture, $\mathrm{C}$ and $\mathrm{N}$ contents, and $\mathrm{Fe}$ and $\mathrm{Al}$ contents in the set-up file. The transport of DOM in the entire soil profile is calculated by solving the convection dispersion equation.

\subsubsection{Biological turnover of organic matter and formation of DOM}

An overview of the individual soil organic matter pools in DAISY and the dynamics between the pools are described in Fig. 1. Further information of the organic 


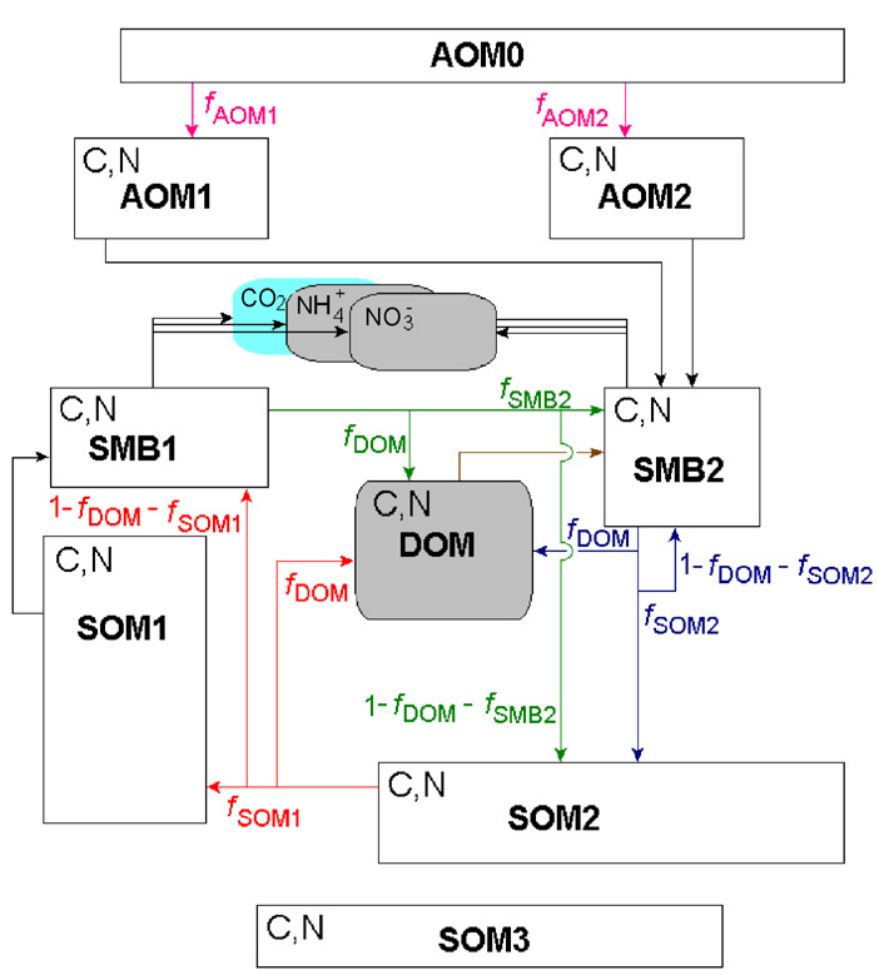

Fig. 1. Relationships between the soil organic fractions in the DAISY model showing the flow partitioning coefficients, $f_{X}$, of flow between the organic pools $X$. AOM1 and AOM2 correspond to the slowly and easily degradable added organic matter, respectively. SOM1 and SOM2 correspond to slowly and easily degradable soil organic matter, respectively. SOM3 is inert soil organic matter. The soil microbial biomass is subdivided into SMB1 and SMB2, which refer to the stable and the dynamic fractions, respectively.

matter model in DAISY is given by Jensen et al. (2001). The soil microbial biomass (SMB) is classified into two pools with different turnover rates, a stable (SMB1) as well as a dynamic microbial biomass pool (SMB2). Additionally, dead native soil organic matter (SOM) is divided into recalcitrant and less recalcitrant pools with different turnover rates referred to as SOM1, SOM2 and SOM3. The SOM1 pool represents chemically stabilized organic matter and the SOM2 pool represents the most bioavailable SOM fraction. Almost inert, humified organic matter is represented by the SOM3 pool. Added organic matter (AOM) represents inputs of new organic substances to the soil system. Input of new organic matter is distributed between two pools, AOM1 and AOM2, which consist of respectively, relatively slowly and easily degradable organic matter. For every new input of organic fertilizer or crop residues a new set of AOM pools is defined (Fig. 1).

Each organic pool in DAISY is quantified in terms of $\mathrm{C}$ and $\mathrm{N}$. The turnover of the organic pools is described by first-order reaction kinetics which is a very simple and well approved approach (Groenendijk and Kroes, 1999; Petersen et al., 2005; Rey and Jarvis, 2006). The turnover rate of each pool is characterized by a turnover rate coefficient, which in turn depends on external variables such as soil temperature, water pressure potential, and clay content.
The effects of temperature and soil water potential have optimums at $37^{\circ} \mathrm{C}$ and $3.2-32 \mathrm{kPa}$, respectively. The effect of clay on the turnover rates increase with decreasing clay contents below $25 \%$ clay. The turnover of the organic matter pools is calculated for each time step $(1 \mathrm{~h})$. The allocation of transformed organic matter or new AOM inputs to the soil system are given by the flow partitioning coefficients, $f_{X}$ (Fig. 1). The arrows in the figure represent the flow directions of organic matter transformations. For instance, the DOM pool receives inputs from the SMB1, SMB2 and SOM2 pools every time step. Additionally, the DOM pool is decomposed at a given turnover rate which is lost from the pool. Hence, the change of the $\mathrm{C}$ content in the DOC pool during one time step due to microbial turnover of organic matter is given by

$$
\left[\frac{\mathrm{d} C_{\mathrm{DOM}}}{\mathrm{d} t}\right]_{\text {turnover }}=f_{\mathrm{DOM}}\left(D_{\mathrm{SMB} 1}+D_{\mathrm{SMB} 2}+\varsigma_{\mathrm{SOM} 2}\right)-\varsigma_{\mathrm{DOM}} \text {, }
$$

where $C_{\mathrm{DOM}}$ is the carbon concentration in the DOC pool, $t$ the time, $\varsigma$ and $D$ are the turnover rate and the death rate, respectively, of the specific pools. The turnover rate coefficients, $k_{x}$, at standard conditions of the SMB pools are the sum of the maintenance rate coefficient, $m_{x}$, and the death rate coefficient, $d_{x}$. The maintenance and respiration is related to the internal turnover of the microbial biomass. The growth respiration depends on the substrate utility coefficient, $E$, which refers to the fraction of substrate, which is incorporated into the microbial biomass. The rest is mineralized, releasing $\mathrm{CO}_{2}$ and $\mathrm{NH}_{4}^{+}$to the soil solution, where $\mathrm{NH}_{4}^{+}$subsequently may be transformed to nitrate during nitrification. Thus, the biological source of DOM in the DAISY model is the microbial biomass and degradation products of the most bioavailable SOM pool. Fresh organic material as manure, slurry, and crop residues is not considered a direct source of DOM.

\subsubsection{Sorption/desorption of DOM}

In DAISY the exchange of DOM between the soil solution and the soil matrix as a result of sorption/desorption during percolation is calculated for each time step in the whole soil profile. The distribution of DOM between the dissolved and solid phase is described based on the kinetics of the exchange process (Gjettermann et al., 2007). Hence, it is assumed that sorption/desorption depends on the deviation between the actual solute concentration and the equilibrium concentration of DOC, $C_{\text {eq }}$. The change with time, $t$, of DOC concentration, $C$, in soil solution due to sorption/desorption is given by

$$
\begin{aligned}
& {\left[\frac{\mathrm{d} C_{\mathrm{DOC}}}{\mathrm{d} t}\right]_{\text {sorption/desorption }}=-k\left(C-C_{\mathrm{eq}}\right),} \\
& {\left[\frac{\mathrm{d} C_{\mathrm{DOC}}}{\mathrm{d} t}\right]_{\text {sorption/desorption }}=-\left[\frac{\mathrm{d} C_{\mathrm{SOM} 2}}{\mathrm{~d} t}\right]_{\text {sorption/desorption }},}
\end{aligned}
$$


where $k$ is the rate coefficient. It is further assumed that only the SOM2 pool has potential for sorption or desorption of DOM. The SOM2 pool represents approximately $2 / 3$ of SOM and has a turnover time of approximately 20 years and represents the DOM sources suggested by Zsolnay (1996) and Hagedorn et al. (2004). Depending on whether the DOC concentration is above or below the $C_{\text {eq }}$, sorption or desorption is activated. During sorption/ desorption of DOM, the change in DOC is related to the change of $\mathrm{C}$ in the SOM2 pool, Eq. (3). The change in DON depends on the $\mathrm{C} / \mathrm{N}$ ratio of the SOM2 pool when desorption occurs, while it is controlled by the $\mathrm{C} / \mathrm{N}$ ratio of the DOM pool when sorption takes place.

\subsection{Experimental data for calibration}

The DAISY model was calibrated on experimental data from a field experiment of a sandy loamy Humic Hapludult (Soil Survey Staff, 1999) (Table 1) at Research Centre Foulum located in the central part of Jutland, Denmark (Vinther et al., 2006; Gjettermann et al., 2007). The field experiment was established to study the first-year effects on crop uptake and nutrient fluxes after ploughing grassclover swards. The experiment included an unploughed 9-year-old grass-clover (treatment A), an 8-year ploughed (treatment B) and a 1-year ploughed grass-clover (treatment C) with increasing $\mathrm{C}$ - and $\mathrm{N}$-input in the crop-soil system, Table 2. Ploughing took place in the spring 2002, after which spring wheat was grown, and leaching of DOM was measured during the subsequent autumn-winter 2002-2003, using Teflon suction cups installed at 30, 60 and $90 \mathrm{~cm}$ depth under the swards. Soil solution samples were analysed for DOC, total $\mathrm{N}$, nitrate and ammonium. DON was calculated as the difference between total $\mathrm{N}$ and inorganic $N$. Details about the field experiment and measurements are given in Vinther et al. (2006). Experi-

Table 1

Soil characteristics of the Foulum soil

\begin{tabular}{llll}
\hline Depth & $\begin{array}{l}\text { Ap horizon } \\
0-30 \mathrm{~cm}(\%)\end{array}$ & $\begin{array}{l}\text { EB horizon } \\
30-70 \mathrm{~cm}(\%)\end{array}$ & $\begin{array}{l}\text { Bt horizon } \\
70-130 \mathrm{~cm}(\%)\end{array}$ \\
\hline $\begin{array}{l}\text { Particle sizes } \\
<2 \mu \mathrm{m}\end{array}$ & 6.8 & 12.6 & 14.8 \\
$2-20 \mu \mathrm{m}$ & 12.7 & 11.4 & 9.7 \\
$20-200 \mu \mathrm{m}$ & 55.4 & 52.4 & 54.4 \\
$200-2000 \mu \mathrm{m}$ & 25.1 & 23.6 & 21.1 \\
Organic matter & & & \\
Total C & 3.04 & 0.14 & 0.09 \\
Total N & 0.20 & 0.01 & 0.01 \\
Al and Fe fractions & & & 0.46 \\
$\mathrm{Al}_{\text {ox }}^{\mathrm{a}}$ & 0.45 & 0.43 & 0.17 \\
Fe $_{\text {cbd }}$ & 0.30 & 0.22 & \\
\hline
\end{tabular}

a ox: Al extractable by ammonium oxalate (Schwertmann, 1964).

bcbd: Fe extractable with citrate-bicarbonate-dithionite (Mehra and Jackson, 1960). ments on mobilization of DOM were carried out on soil samples collected from the same field (Gjettermann et al., 2007).

\subsection{Parameterization}

\subsubsection{Hydraulic properties and weather data}

Retention curve characteristics and hydraulic conductivity were estimated partly from measured hydraulic properties (Iversen, unpublished observations) and partly by the HYPRES pedotransfer functions (Wösten et al., 1998), Table 3. The highest position of the groundwater table was observed at a depth of $130 \mathrm{~cm}$ during winter while the lowest depth obtained during summer was set at $180 \mathrm{~cm}$.

\subsection{DOC sorption and desorption}

To parameterize the equilibrium concentration of DOC, $C_{\text {eq }}$, a pedotransfer function producing parameters for the initial mass (IM) isotherm has been applied (Gjettermann et al., 2007). The IM isotherm developed by Nodvin et al. (1986) is able to quantify the amount of DOC and DON removed or released to the solution by the soil (Moore et al., 1992; Kaiser and Zech, 2000). In this approach the slope of the IM isotherm, $m$, represents the partitioning coefficient of DOC, and the intercept of the linear regression, $b$, refers to the amount of DOC released from the soil when a solution with a zero sorbate concentration is added (Nodvin et al., 1986). The values of $m$ and $b$ can be used to estimate the DOC equilibrium concentration, $C_{\mathrm{eq}}$ :

$C_{\mathrm{eq}}=\frac{b}{m} \frac{M}{V}$,

where $M$ is the soil mass $(\mathrm{kg})$ and $V$ is the volume (1) of the solution in batch sorption experiments. Gjettermann et al. (2007) showed that the $C_{\text {eq }}$ values derived from the IM isotherm changes with time, but that a "true" and constant $C_{\text {eq }}$ is obtained at longer reaction times.

Pedotransfer functions exist to predict values of $m$ and $b$ for DOC as a function of different soil properties (Moore et al., 1992; Kaiser et al., 1996; Neff and Asner, 2001). The pedotransfer functions by Moore et al. (1992) were found to be able to describe IM DOC isotherms for the Foulum soil (Gjettermann, 2005). The pedotransfer functions used for estimating the two parameters, $m$ and $b$, have been developed by Moore et al. (1992):

$m=0.451+0.02 \log \left(\mathrm{Fe}_{\mathrm{cbd}}\right)+0.032 \sqrt{\mathrm{Al}_{\mathrm{ox}}}+0.064 \log (\mathrm{OC})$,

$b=0.145+0.103 \log (\mathrm{OC})-0.055 \sqrt{\mathrm{Al}_{\mathrm{ox}}}-0.045 \log \left(\mathrm{Fe}_{\mathrm{cbd}}\right)$,

where $\mathrm{OC}, \mathrm{Al}_{\mathrm{ox}}$ and $\mathrm{Fe}_{\mathrm{cbc}}$ represent the contents (in mass \%) of organic $\mathrm{C}$, oxalate extractable aluminium and dithionitecitrate-bicarbonate extractable iron (Table 1). The parameters $m$ and $b$ are given as fraction and in units of $\mathrm{g} \mathrm{kg}^{-1}$, respectively. The estimated parameters of $m, b$ and 
Table 2

Cropping sequence, management, total $\mathrm{C}$ and $\mathrm{N}$ input in the three treatments

\begin{tabular}{|c|c|c|c|}
\hline Year & Treatment A & Treatment B & Treatment $\mathrm{C}$ \\
\hline 1993 & Undersown grass-clover & Undersown grass-clover & Undersown grass-clover \\
\hline 1994 & 1-year grass-clover & 1-year grass-clover & 1-year grass-clover \\
\hline 1995 & 2-year grass-clover & 2-year grass-clover & 2-year grass-clover \\
\hline 1996 & 3-year grass-clover & 3-year grass-clover & 3-year grass-clover \\
\hline 1997 & 4-year grass-clover & 4-year grass-clover & Barley with undersown ryegrass \\
\hline 1998 & 5-year grass-clover & 5-year grass-clover & Wheat with undersown ryegrass \\
\hline 1999 & 6-year grass-clover & 6-year grass-clover & Barley with undersown ryegrass \\
\hline 2000 & 7-year grass-clover & 7-year grass-clover & Barley with undersown grass-clover \\
\hline 2001 & 8-year grass-clover & 8-year grass-clover & 1-year grass-clover \\
\hline \multirow[t]{4}{*}{2002} & 9-year grass-clover & Rotovated on March 22 & Rotovated on March 22 \\
\hline & & Ploughed on April 2 & Ploughed on April 2 \\
\hline & & Wheat with undersown ryegrass sown on April 5 & Wheat with undersown ryegrass sown on April 5 \\
\hline & & Wheat harvested August 20 & Wheat harvested August 20 \\
\hline Sampling & Grass-clover & Wheat stubble & Wheat stubble \\
\hline C-input ${ }^{\mathrm{a}}$ & $78,200 \mathrm{~kg} \mathrm{C} \mathrm{ha}^{-1}$ & $133,000 \mathrm{~kg} \mathrm{C} \mathrm{ha}^{-1}$ & $148,000 \mathrm{~kg} \mathrm{C} \mathrm{ha}^{-1}$ \\
\hline $\mathrm{N}$-input ${ }^{\mathrm{b}}$ & $1700 \mathrm{~kg} \mathrm{Nha}^{-1}$ & $3700 \mathrm{~kg} \mathrm{Nha}^{-1}$ & $4400 \mathrm{~kg} \mathrm{Nha}^{-1}$ \\
\hline
\end{tabular}

${ }^{\mathrm{a}}$ Input given as sum of fertiliser and net photosynthesis.

${ }^{\mathrm{b}}$ Input given as sum of fertiliser, atmospheric $\mathrm{N}$ deposition and $\mathrm{N}$ fixation by clover.

Table 3

Soil hydraulic parameters for the van Genuchten retention curve model and the hydraulic conductivity estimated from measurements (Iversen, 2004) and by the HYPRES ${ }^{\mathrm{a}}$ functions for Foulum soil materials

\begin{tabular}{|c|c|c|c|c|c|c|}
\hline Depth $(\mathrm{cm})$ & $\theta_{\text {residual }}\left(\mathrm{cm}^{3} \mathrm{~cm}^{-3}\right)$ & $\theta_{\text {saturation }}\left(\mathrm{cm}^{3} \mathrm{~cm}^{-3}\right)$ & $\alpha\left(\mathrm{cm}^{-1}\right)$ & $n$ & $L$ & $K_{\mathrm{s}}\left(\mathrm{cm} \mathrm{h}^{-1}\right)$ \\
\hline \multicolumn{7}{|c|}{ Estimated from measurements ${ }^{\mathrm{b}}$} \\
\hline $0-20$ & 0.05 & 0.573 & 0.032 & 1.307 & 0.500 & 15.069 \\
\hline $20-40$ & 0.05 & 0.425 & 0.043 & 1.307 & 0.500 & 4.952 \\
\hline $40-60$ & 0.05 & 0.351 & 0.022 & 1.533 & 0.500 & 4.666 \\
\hline \multicolumn{7}{|c|}{ Estimated from the HYPRESS function } \\
\hline $70-130$ & 0.05 & 0.297 & 0.055 & 1.202 & -1.485 & 0.452 \\
\hline $130-200$ & 0.05 & 0.288 & 0.397 & 1.191 & -1.514 & 0.288 \\
\hline
\end{tabular}

${ }^{\mathrm{a}}$ Hypres solution scheme (Wösten et al., 1998).

${ }^{\mathrm{b}}$ Data are averages of 4 replicates.

Table 4

DOM sorption parameters for the Foulum field soil given by Eqs. (4)-(6)

\begin{tabular}{lccl}
\hline & Ap horizon & EB horizon & Bt horizon \\
\hline$m\left(\mathrm{~g} \mathrm{~kg}^{-1}\right)$ & 0.492 & 0.405 & 0.390 \\
$B$ & 0.181 & 0.049 & 0.029 \\
$C_{\mathrm{eq}}{ }^{\mathrm{a}}\left(\mathrm{mg} \mathrm{l}^{-1}\right)$ & 31.9 & 10.4 & 6.6 \\
\hline
\end{tabular}

${ }^{a}$ Assuming a soil:solution ratio of $0.087 \mathrm{kgl}^{-1}$ in Eq. (4) as used by Gjettermann et al. (2007).

$C_{\text {eq }}$ for the Foulum soil are listed in Table 4. The sorption and desorption rate coefficient $k$ in Eq. (2) were determined by fitting to batch sorption experiments (Gjettermann et al., 2007). In the simulations, a sorption/ desorption rate coefficient of $8.4 \times 10^{-2} \mathrm{~d}^{-1}$ in all depths was used as a starting value. However, as described later in Section 3.1 , the rate coefficient in the topsoil $(0-30 \mathrm{~cm})$ was recalibrated to $1.2 \times 10^{-2} \mathrm{~d}^{-1}$.

\subsubsection{Turnover of organic matter}

Several experimental studies have been considered in relation to parameterization of the organic matter module in DAISY, both long-term field experiments and shortterm incubation experiments with different applied organic fertilizers (Jensen et al., 2001). For each horizon defined in the set-up of the model, the organic pools were initialized by the soil $\mathrm{C}$ and $\mathrm{N}$ content in each horizon (Table 1) by assuming equilibrium between the SOM, AOM and SMB pools. A warm-up period is required to obtain a dynamic balance in the soil water, nitrogen and ammonium contents along with the organic matter pools, which depends on the soil treatments. The warm-up period was the previous 9 years of soil treatment before sampling (Table 2).

The standard DAISY parameters for organic matter transformations comprising coefficients of flow partitioning, the substrate utility, turnover rate, maintenance, and death rate for the SOM and SMB pools (Jensen et al., 2001) are listed in Table 5 and have been used in this study. 
Table 5

DOM parameters and standard parameterization of the organic matter module in DAISY

\begin{tabular}{|c|c|c|c|c|c|}
\hline & SMB1 & SMB2 & SOM1 & SOM2 & DOM \\
\hline $\mathrm{C} / \mathrm{N}$-ratio & 6.7 & 6.7 & 11 & 11 & Variable \\
\hline Flow partitioning coefficient $f_{x}$ & 0 & 1.0 & 0.1 & 0.4 & 0.05 \\
\hline Microbial utility coefficient $E$ & 0.6 & 0.6 & 0.4 & 0.5 & 0.5 \\
\hline Death rate coefficient $d_{x}\left(\mathrm{~d}^{-1}\right)$ & $1.85 \times 10^{-4}$ & $1.0 \times 10^{-2}$ & & & \\
\hline Maintenance coefficient $m_{x}\left(\mathrm{~d}^{-1}\right)$ & $1.80 \times 10^{-3}$ & $1.0 \times 10^{-2}$ & & & \\
\hline Turnover rate coefficient $k_{x}\left(\mathrm{~d}^{-1}\right)$ & $1.98 \times 10^{-3}$ & $2.0 \times 10^{-2}$ & $2.7 \times 10^{-6}$ & $1.4 \times 10^{-4}$ & $3.6 \times 10^{-4 a}\left(3.6 \times 10^{-3 b}\right)$ \\
\hline
\end{tabular}

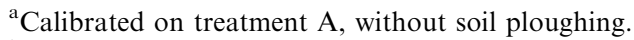

${ }^{\mathrm{b}}$ In parenthesis: calibrated on treatment $\mathrm{B}$, with soil ploughing.

The table also includes the values of DOM parameters that have been used. The microbial substrate utility coefficient of DOM is parameterized like the SOM2 pool, as this pool is an important source of DOM. The turnover of the SOM2 and the SMB pools releases a fraction of metabolites to the DOM pool, which is represented by the flow partitioning coefficient, $f_{\mathrm{DOM}}$, for DOM (Table 5, Fig. 1).

\subsubsection{Simulation of grazing and crop growth}

When the field plots were covered by grass-clover, they were grazed by dairy cattle. Based on grazing experiments described by Søegaard et al. (2001) it was assumed that $70 \%$ of dung and urine per cow is deposited in the field. In 1994, 1995 and 1996 it was found that 233, 307 and $308 \mathrm{~kg} \mathrm{~N} \mathrm{ha}^{-1}$ year $^{-1}$, respectively, was deposited in the field by grazing cows. In the following years it was assumed that $283 \mathrm{~kg} \mathrm{~N}^{-1}$ year $^{-1}$ is deposited in the fields during grazing.

To simulate grazing, the grass-clover has been treated as if it was cut when the crop had reached a certain development stage or when the dry matter content of the crop exceeded $1000 \mathrm{~kg} \mathrm{DM} \mathrm{ha}^{-1}$. At least 10 days separated the cuts. When cutting, $80 \%$ of leaves, stems, and storage organs of the grass-clover were removed from the field and the rest was left as residuals together with $5 \mathrm{~cm}$ stubble. The total biomass production of grass-clover and the $\mathrm{N}_{2}$ fixation by clover were simulated by sowing both clover and ryegrass at the same time.

\subsection{Calibration of the model}

Two parameters have been calibrated: the sorption/ desorption rate coefficient and the turnover rate coefficient of the DOM pool. To identify the magnitude of error between simulated and measured DOC and DON concentrations a statistical indicator, the normalized root mean square error (NRMSE), has been used. The NRMSE is calculated by

$\mathrm{NRMSE}=100 \% \frac{\sqrt{1 / n \sum_{i=1}^{n}\left(P_{i}-M_{i}\right)^{2}}}{1 / n \sum_{i=1}^{n} M_{i}}$, where $P_{i}$ and $M_{i}$ are the predicted and measured concentrations of DOC or DON, respectively, and $n$ is the number of observations. An NRMSE value of $25 \%$ or less was defined as good and values between $25 \%$ and $30 \%$ were acceptable. Different values of sorption/desorption and turnover rates were investigated and the NRMSE was calculated to identify the best DOC simulation in treatment A.

\section{Results}

\subsection{Calibration}

\subsubsection{Calibration of the DOM sorption/desorption rate}

During the calibration, simulations with different parameters values of the DOM turnover rate coefficient and the sorption/desorption rate coefficient have been obtained. Fig. 2 shows the measured DOC concentrations at 30 and $60 \mathrm{~cm}$ depth for treatment A together with the simulated dynamics by use of different values of DOM turnover rate coefficient and the sorption/desorption rate coefficient. A sorption/desorption rate coefficient of $8.4 \times 10^{-2} \mathrm{~d}^{-1}$ was used in the subsoil horizons below $30 \mathrm{~cm}$ depth. Using a relatively high sorption/desorption rate for the $0-30 \mathrm{~cm}$ layer (Fig. 2a), the simulated DOC concentration was almost steady over time at a concentration level close to $C_{\text {eq }}$, which, for the topsoil was $31.9 \mathrm{mgl}^{-1}$ (Table 4). The microbially driven SOM and DOM turnover and change in water content caused fluctuations in DOM concentration in the topsoil. If the sorption/desorption rate coefficient was low in the topsoil, then no immediate buffering of DOM took place and the fluctuations persisted (Fig. 2c-d). In the subsoil, exemplified by $60 \mathrm{~cm}$ depth (Fig. 2e-h), the DOM concentration level appeared unaffected by microbial-driven SOM and DOM turnover and the sorption/ desorption rate in the topsoil.

Table 6 shows the NRMSE between measured and simulated DOC concentrations for treatments A at $30 \mathrm{~cm}$ depth, as a function of different sorption/desorption rates and turnover rates. The lowest NRMSE for the simulations in the topsoil occurred at a sorption/desorption rate coefficient set at $1.2 \times 10^{-2} \mathrm{~d}^{-1}$. In the subsoil (below $30 \mathrm{~cm}$ ) the estimated rate coefficient found in the sorption/desorption experiments of $8.4 \times 10^{-2} \mathrm{~d}^{-1}$ was used resulting in 

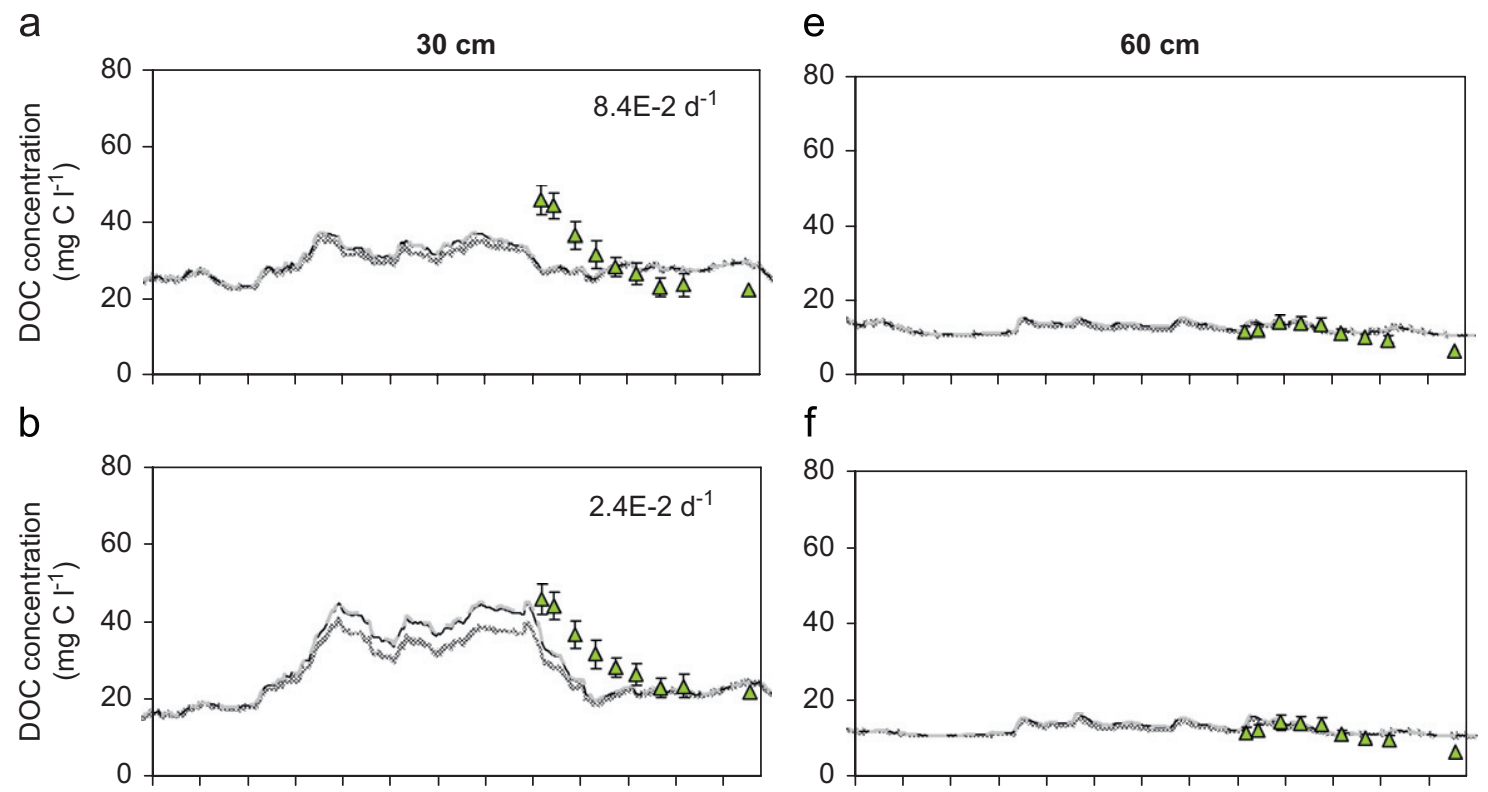

C
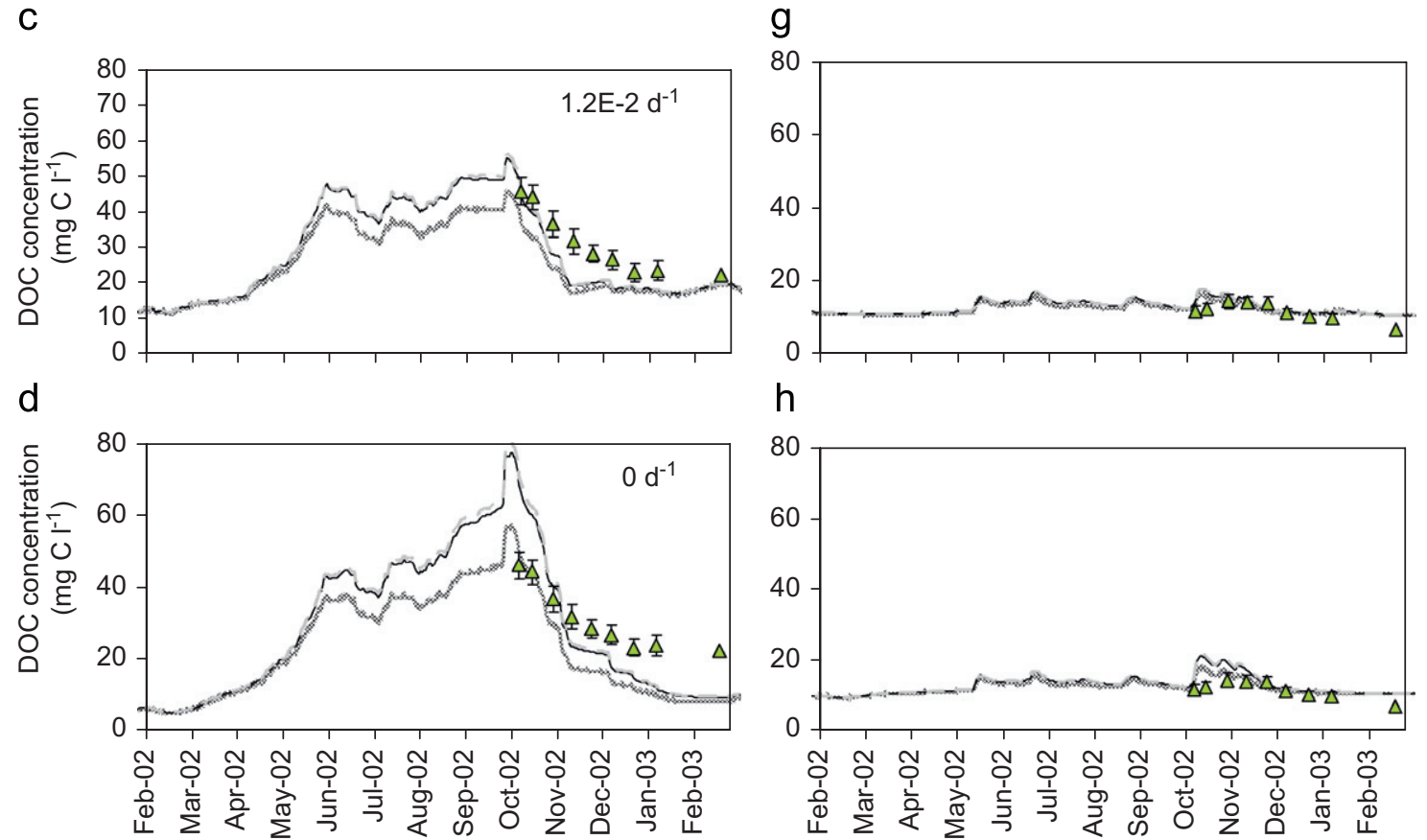

3.6E-3 per day

3.6E-4 per day

$--3.6 E-5$ per day $\Delta$ Samples

Fig. 2. DOC concentration in suction cups (dots) (Vinther et al., 2006) and simulated DOC concentration by the DAISY code (full lines) at $30 \mathrm{~cm}$ (left) and $60 \mathrm{~cm}$ (right) depth in treatment A using turnover rate coefficients of $3.6 \times 10^{-3} \mathrm{~d}^{-1}, 3.6 \times 10^{-4} \mathrm{~d}^{-1}$ and $3.6 \times 10^{-5} \mathrm{~d}^{-1}$, respectively, and applying sorption/desorption rate coefficients in the topsoil of (a, e) $8.4 \times 10^{-2} \mathrm{~d}^{-1}$, (b, f) $2.4 \times 10^{-2} \mathrm{~d}^{-1}$, (c, g) $1.2 \times 10^{-2} \mathrm{~d}^{-1}$, and (d, h) $0 \mathrm{~d}^{-1}$. In the subsoil a sorption/desorption rate coefficient of $8.4 \times 10^{-2}$ was used throughout. Bars indicate standard derivation of 6 measurements.

NRMSE values of $24.4 \%$ and $41.1 \%$ for $60 \mathrm{~cm}$ and $90 \mathrm{~cm}$ depth, respectively.

\subsubsection{Calibration of the DOM turnover rate}

The turnover rate coefficient for the DOM pool in Table 5 was calibrated using the observations of treatment A at $30 \mathrm{~cm}$ depth as most microbial activity occurs in the topsoil and it does not influence the DOC level in the subsoil (Fig. 2). Increasing the turnover rate coefficient from $3.6 \times 10^{-5}$ to $3.6 \times 10^{-3} \mathrm{~d}^{-1}$ resulted in a considerable decrease in the DOC fluctuations in the topsoil. For instance, a simulated peak in DOC concentration during August 2002 in treatment A was reduced from approximately 80 to $58 \mathrm{mg}^{-1}$ at $30 \mathrm{~cm}$ depth (Fig. 2d) when no sorption/desorption occurred. A turnover rate coefficient of $3.6 \times 10^{-4} \mathrm{~d}^{-1}$ was chosen for all depths because it 
Table 6

Normalized root mean square error (NRMSE) in percent, between measured and simulated DOC concentrations for treatment A at $30 \mathrm{~cm}$ depth, as a function of different sorption/desorption and turnover rates

\begin{tabular}{lllll}
\hline $\begin{array}{l}\text { DOM turnover } \\
\text { rate coefficient } \\
\left(\mathrm{d}^{-1}\right)\end{array}$ & \multicolumn{5}{l}{ Sorption/desorption rate $\left(\mathrm{d}^{-1}\right)$} \\
\cline { 2 - 5 } & $8.4 \times 10^{-2}$ & $2.4 \times 10^{-2}$ & $1.2 \times 10^{-2}$ & 0 \\
\hline $3.6 \times 10^{-3}$ & 32.6 & 32.5 & 30.5 & 34.9 \\
$3.6 \times 10^{-4}$ & 31.7 & 27.2 & 22.1 & 38.8 \\
$3.6 \times 10^{-5}$ & 31.6 & 26.6 & 21.4 & 41.0 \\
\hline
\end{tabular}

resulted in an acceptably low NRMSE value of $22.1 \%$ together with a sorption/desorption rate coefficient of $1.2 \times 10^{-2} \mathrm{~d}^{-1}$ (Table 6) and the best fit in the subsoil with a sorption/desorption rate coefficient of $8.4 \times 10^{-2} \mathrm{~d}^{-1}$.

\subsection{Water balance, DOC and DON leaching, crop production and organic matter}

For the simulated period (including the warm-up period), January 1993-April 2003, the total precipitation and the simulated actual evapotranspiration corresponded to average yearly values of $820 \mathrm{~mm}$ precipitation and $570 \mathrm{~mm}$ evapotranspiration. During the period, approximately $250 \mathrm{~mm}$ per year of water percolated through matrix (93\% of total percolation) and macropores $(7 \%$ of total percolation). Sampling of DOC and DON from suction cups started in October 2002 when the soil water content was at or above field capacity. For treatments A and $\mathrm{B}$ the simulated average annual DOC and DON exports in the period 1994-2003, were $16.1 \mathrm{~kg} \mathrm{DOC} \mathrm{ha}^{-1}$ and $1.7 \mathrm{kgDON} \mathrm{ha}^{-1}$, respectively. For treatment $\mathrm{C}$ the simulated average annual DOC and DON exports were $15.4 \mathrm{~kg} \mathrm{DOC} \mathrm{ha}^{-1}$ and $1.4 \mathrm{~kg} \mathrm{DON} \mathrm{ha}^{-1}$, respectively.

In 2002 the dry matter production rates of harvested wheat were simulated as 8.9 and $9.6 \mathrm{Mg} \mathrm{ha}^{-1}$ for treatments $\mathrm{B}$ and $\mathrm{C}$, respectively. According to measured data, 9.3 $\mathrm{Mg} \mathrm{ha}^{-1}$ was harvested in 2002; hence, the simulations estimated the crop yield very well. In the simulated period the grass-clover had an estimated $\mathrm{N}_{2}$ fixation of approximately $200 \mathrm{~kg} \mathrm{Nha}^{-1}$ year $^{-1}$ (not shown), which corresponded fairly well with earlier measurements in the same experimental field. In 1994 and 1995, the $\mathrm{N}_{2}$ fixations were estimated as 232 and $408 \mathrm{~kg} \mathrm{Nha}^{-1}$ year $^{-1}$, respectively (Søegaard et al., 2001), and in 1997 and 1998 as 263 and $124 \mathrm{~kg} \mathrm{~N} \mathrm{ha}^{-1}$ year $^{-1}$, respectively (Hansen and Vinther, 2001). In 2001, the $\mathrm{N}_{2}$ fixation was estimated as $101 \mathrm{~kg} \mathrm{~N}^{-1}$ year $^{-1}$ (Eriksen et al., 2004). Continuous clover-grass in treatment A increased the SOM content in the simulations from approximately 140 to $143 \mathrm{t} \mathrm{C} \mathrm{ha}^{-1}$ in the period of 1995-2003 which corresponds to an increase of $1.9 \%$. Continuous crop rotation in treatment $\mathrm{C}$ reduced the SOM content by $1.3 \%$ in the same period. Hence, the SOM dynamics is slow but affected by the soil treatment over time.

\subsubsection{Temporal variation of DOC and DON in soil solution}

Comparison of the simulated and measured DOC concentrations for the last year of the experiment at different depths and for all three soil treatments are shown in Fig. 3. The simulated DOC concentrations obtained by the parameters calibrated on treatments A and B are shown by the full and broken lines. In general, the simulated and measured DOC concentrations decreased with depth for all the soil treatments. For treatments $\mathrm{B}$ and $\mathrm{C}$ for which the parameters obtained for treatment A were used (full line), the simulated DOC concentrations showed stronger fluctuations than the measured DOC concentrations resulting in a little less favourable fits than for treatment A (Table 7).

Treatment A was not ploughed while treatments B and C were. Thus, the calibration of treatment A did not include effect of ploughing. Hence, instead of using parameters calibrated from treatment $\mathrm{A}$, treatment $\mathrm{B}$ was used for recalibration of the DOM parameters and the parameters tested on treatment $\mathrm{C}$. The goodness of fit NRMSE values for treatments $\mathrm{B}$ and $\mathrm{C}$ are shown in brackets in Table 7. When the DOM turnover rate coefficient was increased from $3.6 \times 10^{-4}$ to $3.6 \times 10^{-3} \mathrm{~d}^{-1}$ and the sorption/ desorption rate coefficient increased from $1.2 \times 10^{-2}$ to $2.4 \times 10^{-2} \mathrm{~d}^{-1}$ the model resulted in rather good simulations with NRMSE values below $25 \%$ in the topsoil for treatments $\mathrm{B}$ and $\mathrm{C}$.

At the depth of $60 \mathrm{~cm}$, the simulated DOC concentrations fitted the observed data very well for treatments A and $\mathrm{C}$ using the calibration for treatment $\mathrm{A}$. For treatment $\mathrm{B}$ the simulation overestimated the DOC concentration somewhat (Fig. 3). Reducing the $C_{\mathrm{eq}}$ from 10.4 to $3.8 \mathrm{mgl}^{-1}$, corresponding to a lower content of $\mathrm{Al}, \mathrm{Fe}$ or organic $\mathrm{C}$ in the $\mathrm{EB}$ horizon in the pedotransfer model (Eqs. (5) and (6)), decreased the NRMSE value from $111 \%$ to $38 \%$.

At $90 \mathrm{~cm}$ depth the DOC concentrations were simulated very well for treatments $\mathrm{B}$ and $\mathrm{C}$, using the calibration for treatment $\mathrm{A}$, resulting in NRMSE values of $21.3 \%$ and $26.2 \%$, respectively. In treatment $A$ the DOC concentration was considerably underestimated. Increasing the $C_{\text {eq }}$ from 6.6 to $8.4 \mathrm{mgl}^{-1}$ reduced the NRMSE value from $41.6 \%$ to $29 \%$.

As a further test of the validity of the DOM model, the DON concentrations were simulated (Fig. 4). The simulated DON concentration obtained by the DOM parameters calibrated on treatments $\mathrm{A}$ and $\mathrm{B}$ are shown by the full and broken lines, respectively. In the topsoil, measured DON concentrations also showed fluctuations over time with maximum during spring and summertime, and minimum during fall and wintertime (Fig. 4). It should be noticed that there has been no calibration of the DON simulations and that the uncertainty of the DON measurements are high with coefficient of variation in the range of $100-300 \%$ (Vinther et al., 2006). The simulated DON dynamics in the topsoil resulted in relatively high NRMSE values (Table 8). In the simulations with 

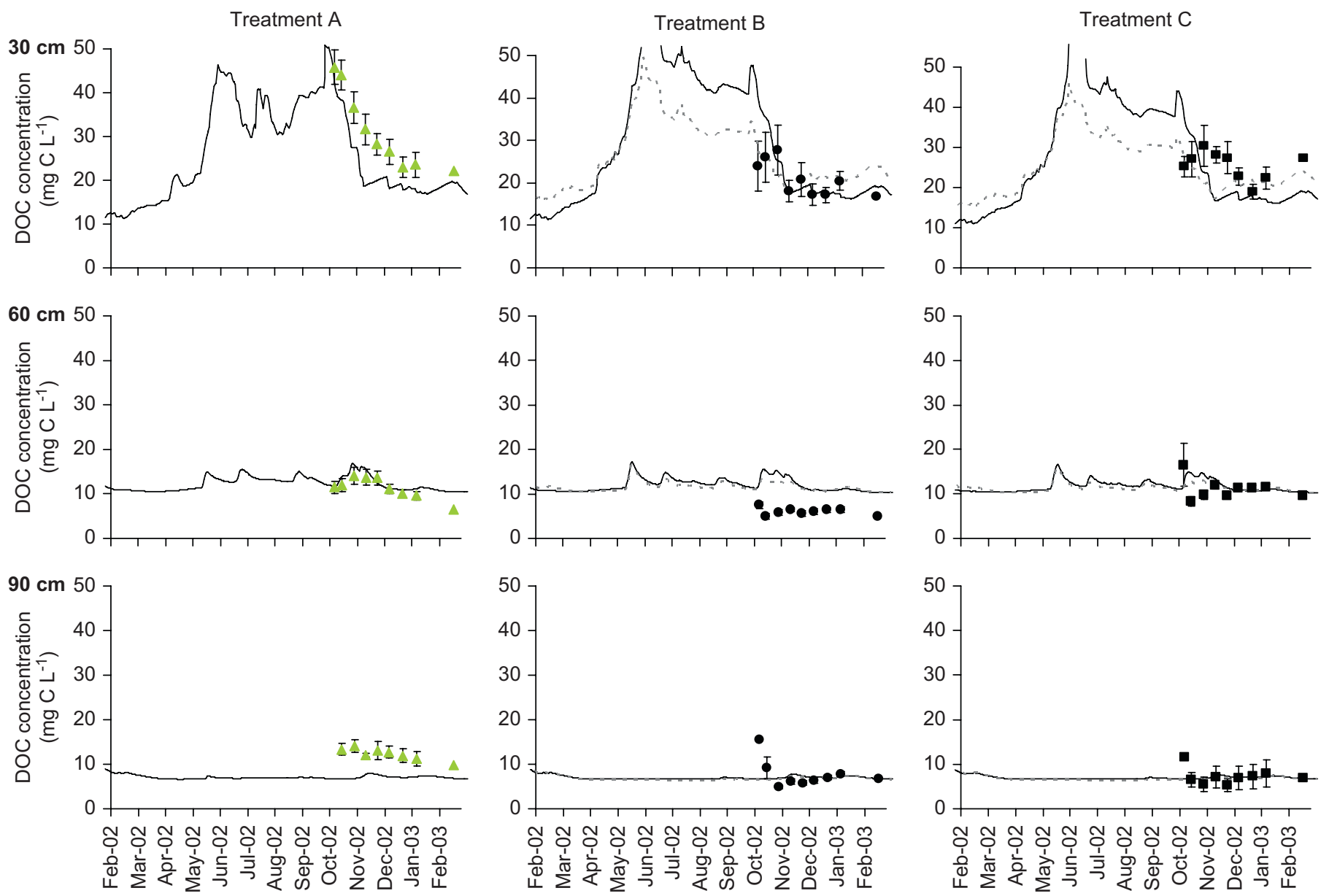

Fig. 3. DOC concentration in suction cups (dots) (Vinther et al., 2006) and simulated DOC concentration by the DAISY code calibrated on treatment A (full lines) and calibrated on treatment B (broken line) at 30,60 and $90 \mathrm{~cm}$ depths in the three treatments. Bars indicate standard derivation of 6 measurements.

Table 7

Normalized root mean square error (NRMSE) in percent, between measured and simulated DOC concentrations using parameters calibrated on treatment $\mathrm{A}^{\mathrm{a}}$ and treatment $\mathrm{B}^{\mathrm{b}}$ (in parenthesis)

\begin{tabular}{llrl}
\hline Depth $(\mathrm{cm})$ & Treatment A & Treatment B & Treatment C \\
\hline 30 & 22.1 & $33.1(18.7)$ & $31.5(22.3)$ \\
60 & 24.4 & $111.6(96.8)$ & $28.4(23.4)$ \\
90 & 41.6 & $21.3(20.3)$ & $26.2(26.5)$ \\
\hline
\end{tabular}

${ }^{\mathrm{a} D O M}$ turnover rate coefficient of $3.6 \times 10^{-4} \mathrm{~d}^{-1}$ and sorption/ desorption rate of $1.2 \times 10^{-2} \mathrm{~d}^{-1}$ in the topsoil and $8.4 \times 10^{-2} \mathrm{~d}^{-1}$ in the subsoil.

${ }^{\mathrm{b}}$ DOM turnover rate coefficient of $3.6 \times 10^{-3} \mathrm{~d}^{-1}$ and sorption/ desorption rate of $2.4 \times 10^{-2} \mathrm{~d}^{-1}$ in the topsoil and $8.4 \times 10^{-2} \mathrm{~d}^{-1}$ in the subsoil.

recalibration on treatment $B$, the simulation was slightly better in 30 and $60 \mathrm{~cm}$ depths, but not in $90 \mathrm{~cm}$ depth. Some of the DOC and DON measurements, particularly in $90 \mathrm{~cm}$ depth showed unexpected C:N ratios. In Fig. 4 the DON measurements showing $\mathrm{C}: \mathrm{N}$ ratios less than 5 and greater than 15 have been marked by open symbols.
Additionally, for the DON data with unusual $\mathrm{C}: \mathrm{N}$ ratios measured DON fluctuations do not correlate with the fluctuations in DOC. If these data are excluded the DON levels at 60 and $90 \mathrm{~cm}$ depths appear to be rather constant.

\section{Discussion}

\subsection{Mobility of DOM}

The average yearly DOC net export from the soil in the three treatments was approximately $15-16 \mathrm{~kg} \mathrm{Cha}^{-1}$. For DON the yearly net export is in the range $1.5-1.7 \mathrm{~kg} \mathrm{Nha}^{-1}$. It has been reported that DOC export from many catchments in Europe falls in the range 7.6-89.9 $\mathrm{kg} \mathrm{Cha}^{-1}$ year $^{-1}$, with the largest contributions coming from heather moorland rather than grassland (Hope et al., 1994). McTiernan et al. (2001) found that total DOC exported from ten hydrologically isolated 1 ha grazed grassland plots in England varied from 42 to $118 \mathrm{~kg} \mathrm{Cha}^{-1}$ over a 2-month period (November 16January 23). Hence, the leaching of DON and DOC 
Treatment A
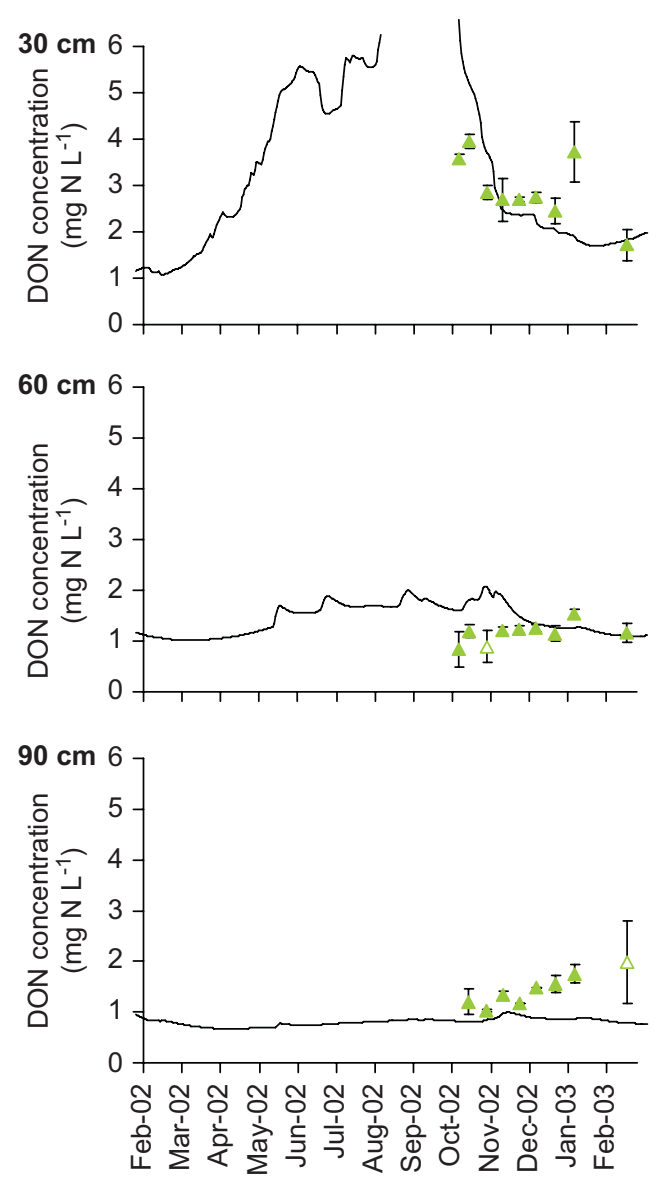

Treatment B
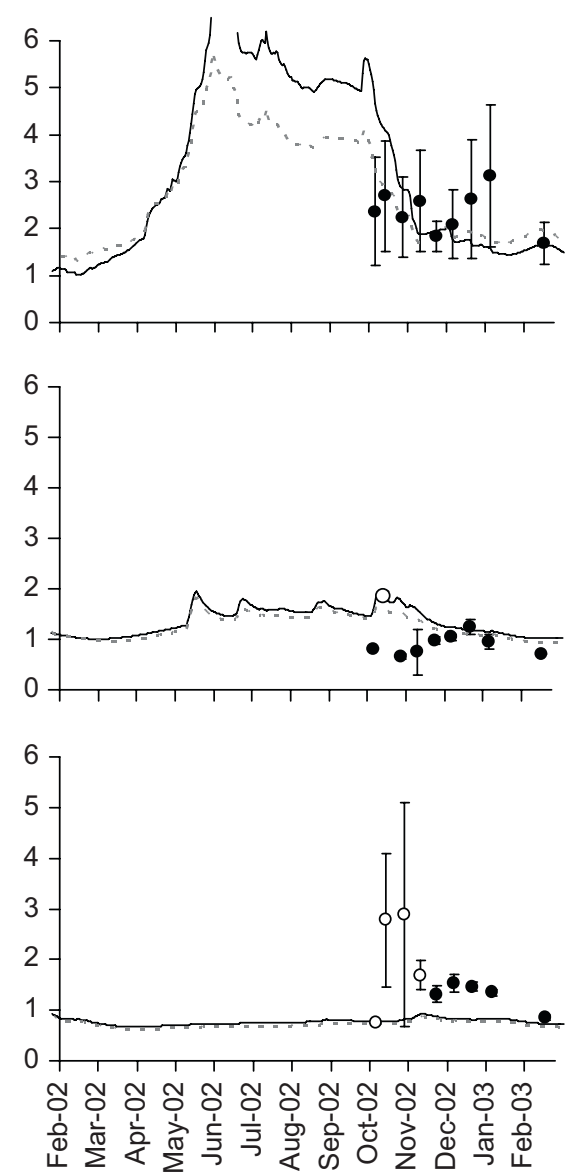

Treatment C
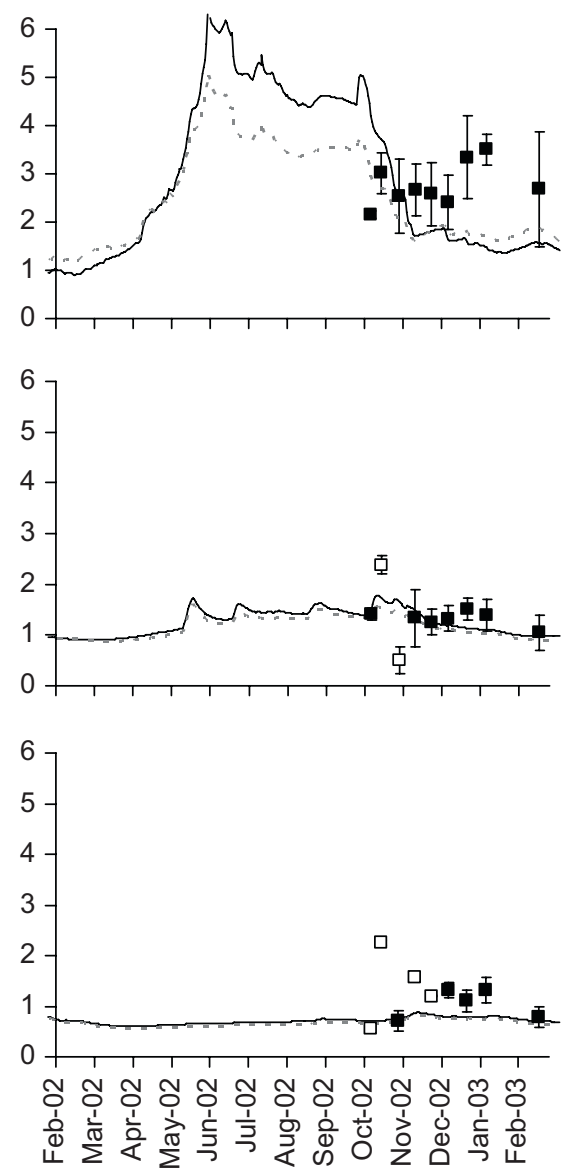

Fig. 4. DON concentration in suction cups (dots) (Vinther et al., 2006) and simulated DON concentration by the DAISY code calibrated on treatment A (full lines) and calibrated on treatment B (broken line) at 30,60 and $90 \mathrm{~cm}$ depths in the three treatments. Open symbols refer to DON and DOC concentrations resulting in $\mathrm{C}: \mathrm{N}$ ratios below 5 or above 15. Bars indicate standard derivation of 6 measurements.

Table 8

Normalized root mean square error (NRMSE) in percent between measured and simulated DON concentrations using parameters calibrated on treatment $\mathrm{A}^{\mathrm{a}}$ and treatment $\mathrm{B}^{\mathrm{b}}$ (in parenthesis)

\begin{tabular}{llll}
\hline Depth $(\mathrm{cm})$ & Treatment A & Treatment B & Treatment C \\
\hline 30 & 44.2 & $48.0(28.3)$ & $46.9(37.1)$ \\
60 & 49.1 & $36.2(34.8)$ & $35.3(35.6)$ \\
90 & 45.5 & $48.9(51.7)$ & $51.6(54.3)$ \\
\hline
\end{tabular}

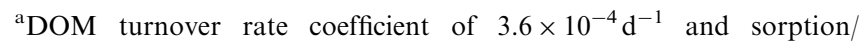
desorption rate of $1.2 \times 10^{-2} \mathrm{~d}^{-1}$ in the topsoil and $8.4 \times 10^{-2} \mathrm{~d}^{-1}$ in the subsoil.

${ }^{\mathrm{b}}$ DOM turnover rate coefficient of $3.6 \times 10^{-3} \mathrm{~d}^{-1}$ and sorption/ desorption rate of $2.4 \times 10^{-2} \mathrm{~d}^{-1}$ in the topsoil and $8.4 \times 10^{-2} \mathrm{~d}^{-1}$ in the subsoil.

observed for the three treatments studied was low compared to other studies which could be due to the soil buffering capacity of DOM. However, the model has only been validated over a few months and the rest of the year was outside the calibration data set. Therefore the simulated annual export must be considered with caution.

\subsection{Sorption/desorption}

The fluctuations in measured DOC concentrations in the topsoil (Fig. 3) can be related to the microbial activity reflecting the relatively low water content and relatively high temperatures in the spring and summertime. However, the DOC concentrations were buffered by sorption/ desorption which results in less marked fluctuations. To avoid the strong buffering in the simulated DOM concentrations in the topsoil, it was necessary to reduce the sorption/desorption rate coefficient. The sorption/ desorption rate coefficients, which were used as a starting point, had been obtained in batch experiments, which maximize contact between liquid and soil, and which do not take into account diffusion time and unsaturated conditions occurring under field conditions. The relative contribution to DOM from microbial SOM turnover and the chemical/physical SOM stabilization has been a matter of dispute as described in the introduction. Concerning the DOM in the topsoil, this study indicates that the microbial process is very important in the topsoil (Fig. 2). 
In the mineral subsoil the microbial source of DOM is negligible and the level of DOC concentration is dominated by leaching and the sorption/desorption process in the simulations. In general, the DOC concentration levels in the subsoils are simulated well, except for treatment $\mathrm{A}$ at $90 \mathrm{~cm}$ depth and treatment B at $60 \mathrm{~cm}$ depth. However, acceptable simulations could be obtained if $C_{\text {eq }}$ was adjusted. The equilibrium concentration parameter, $C_{\text {eq }}$, given by Eq. (2) is critical for the simulated concentration level, especially in the mineral subsoils. The estimated $C_{\mathrm{eq}}$ for each horizon in one soil profile (Table 4) represents the whole field in the simulations. However, it is well known that spatial variation of elements in the field, of for instance Al- and Fe-oxides (Bruland and Richardson, 2004; Vaughan et al., 2007), is the norm rather than the exception both in the vertical as well as in the horizontal direction. Therefore, it is difficult to get an exact measure of for instance $C_{\mathrm{eq}}$ for the whole field even if several samples are taken. It was shown that by adjusting the $C_{\text {eq }}$, the deviations between simulations and measurements could be narrowed, which indicate that proper representation of soil heterogeneity with respect to organic matter, Al, and $\mathrm{Fe}$ oxides in the model could improve its precision. However, there is always a general uncertainty associated to a pedotransfer function as not all variables of interest may be included. Hence, the effect of $\mathrm{pH}$, soil solution composition, and $\mathrm{CaCO}_{3}$ content which the pedotransfer functions do not account for might also affect the $C_{\text {eq }}$ and the mobility of DOM (Römkens et al., 1996; Gjettermann et al., 2007).

\subsection{Biological production and decomposition of DOM}

A number of authors have found that decomposition of DOM can be adequately described by simple first-order kinetics. For agricultural soils, turnover rates of DOM have been found to be in the range of $6 \times 10^{-3}$ $10 \times 10^{-3} \mathrm{~d}^{-1}$ (Zsolnay and Steindl, 1991). Turnover rates of cow faeces have been reported to be in the range of $2.9 \times 10^{-3}-8.5 \times 10^{-3} \mathrm{~d}^{-1}$. In the DAISY model, the turnover rate was calibrated to a value of $3.6 \times 10^{-4} \mathrm{~d}^{-1}$ by estimating the best fit between measured and simulated DOC concentrations in treatment $A$. The calibration resulted in a relatively low turnover rate coefficient indicating that DOM may be relatively resistant to degradation. However, ploughing was found to affect the microbial-driven process with an increase in the DOM turnover rate and the estimated value of $3.6 \times 10^{-3} \mathrm{~d}^{-1}$ based on treatment B is of the same magnitude as reported by Zsolnay and Steindl (1991).

Data on change in ${ }^{14} \mathrm{C}$ indicate that most of the DOC in soil is fairly old, at least 30 years at $5 \mathrm{~cm}$ depth (Tegen and Dorr, 1996) and at 10-25 cm (Trumbore et al., 1992), supporting that SOM is the major source of DOM. This is also supported by findings of Hagedorn et al. (2004) who found that the DOC in topsoils contained only $5-10 \%$ of $\mathrm{C}$ which could be attributed to recent additions from the vegetation (throughfall, litter, roots) of spruce and beech. On the contrary, Vinther et al. (2006) working with a coarse sandy soil, showed that DOC and DON concentrations generally were higher under plant cover than under bare soil. Additionally, increasing the period of continuing grass-clover from 3 to 5 years increased the DOC and DON concentrations. This indicates that fresh and relative young organic material can be a more important source of DOC and DON than old humic fractions (Vinther et al., 2006). The study of Haynes (1999) showed that 5 years of grass or grass/clover pasture may cause a significant increase in soil organic matter in the surface $5 \mathrm{~cm}$ of soil. In the DAISY model increasing the SOM content will also increase the DOM concentration. The SOM2 pool has a turnover time of approximately 20 years. Thus, in DAISY the main source of DOM can be attributed to humified material with an age comparable with the findings of Trumbore et al. (1992) and Tegen and Dorr (1996).

The measured DOC concentrations were affected by soil treatment at $30 \mathrm{~cm}$ depth as the incorporation of crop residues did affect the DOC dynamics in the topsoil and the DOC concentrations were significantly higher in treatment A than in treatments B and C. This tillage effect was not taken into account in the simulations when the model was calibrated using treatment $\mathrm{A}$. The recalibration on treatment $B$ resulted in much better fit of both treatments $B$ and $\mathrm{C}$ and illuminated some of the discrepancies. The simulations show that soil ploughing increases the turnover rate of DOM. Ploughing may increase the availability of oxygen resulting in lower DOC concentrations due to mineralization.

The different soil treatments did not noticeably affect the measured or simulated DON concentration during the sampling period the following autumn and winter (Fig. 4). Large standard deviations were found for the measured DON concentrations, which makes comparisons with the simulations more difficult. However, the observed partly contrasting temporal dynamics of DOC and DON indicates that different DOM fractions may have different mobility over time which is supported by studies showing that hydrophobic and hydrophilic DOM fractions have different $\mathrm{C} / \mathrm{N}$ ratios and mobility (e.g. Kaiser et al., 1996). Although the model has not been calibrated for DON, the simulation results of DON concentrations in the subsoil were at the observed concentration levels, allowing the model to be used to quantify DON leaching.

\section{Conclusions}

A new DOM model has been developed and implemented into the DAISY code. The DOM model has been tested on three treatments and the results have highlighted some processes, which strengthen the model concept and areas which require further model development.

In the parameterization of the model, it has been assumed that relatively stable soil organic matter, and not easily degradable dissolved organic matter such as root 
exudates and organic fertilizers, is the source of DOM. For treatment $\mathrm{A}$ this assumption seemed to be acceptable, but for treatments $\mathrm{B}$ and $\mathrm{C}$ where incorporation of crop residues and organic fertilizer occurred, the simulated dynamics in the topsoil was not well described which may be attributed to the fact that the necessary tillage effect was not simulated in the model. However, the effect of tillage can be mimicked by adjusting the turnover rate coefficient. Thus, the simulated microbial-driven DOM production has some limitations in the topsoil and must be investigated further.

The kinetic concept for describing the distribution of DOM between the solution and solid phase appears a viable approach especially for the subsoil. However, it was necessary to recalibrate the sorption/desorption rate coefficient in the topsoil obtained from batch experiments. It is critical for the simulations that the right $C_{\mathrm{eq}}$ is estimated from the pedotransfer functions. If $C_{\mathrm{eq}}$ was successfully estimated by the pedotransfer function it was possible to simulate the DOC concentration in the subsoil. Thus, there is a strong need to develop a better method to estimate $C_{\mathrm{eq}}$ in the field.

The model confirms the measurements, and illustrates that DOC and DON concentrations show less variability in the subsoils due to soil buffering. In spite of difficulties in describing the DOC dynamics of the topsoil, the DOM module is able to simulate the subsoil concentration level of DOC, and also - but with more uncertainty - the DON concentration level. However, there is a strong need to further test and develop the model at field scale.

\section{Acknowledgements}

The results presented here were part of a research program "Regional Groundwater Protection by Optimized Organic Farming Systems" financed by Danish Research Centre for Organic Farming, in conjunction with an industrial Ph.D. project at DHI Water \& Environment in association with The University of Copenhagen, Faculty of Life Sciences, financed by The Danish Academy of Technical Science.

\section{References}

Abrahamsen, P., Hansen, S., 2000. DAISY: an open soil-crop-atmosphere system model. Environmental Modelling and Software 15, 313-330.

Bruland, G.L., Richardson, C.J., 2004. A spatially explicit investigation of phosphorus sorption and related soil properties in two riparian wetlands. Journal of Environmental Quality 33, 785-794.

DAISY, 2007. New homepage: 〈http://www.dina.kvl.dk/ daisy/〉. Follow the link "old homepage" for old version of the DAISY software, documentation, news, tutorials, etc.

de Willigen, P., 1991. Nitrogen turnover in the soil-crop system; comparison of fourteen simulation models. Fertilizer Research 27, 141-149.

Diekkrüger, B., Søndgerath, D., Kersebaum, K.C., McVoy, C.W., 1995. Validity of agroecosystem models. A comparison of results of different models applied to the same data set. Ecological Modelling 81, 3-29.
Eriksen, J., Vinther, F.P., Søegaard, K., 2004. Nitrate leaching and N2 fixation in grasslands of different composition, age and management. Journal of Agricultural Science 142, 141-151.

Evans, C.D., Monteith, D.T., Cooper, D.M., 2005. Long-term increases in surface water dissolved organic carbon: observations, possible causes and environmental impacts. Environmental Pollution 137, 55-71.

Gjettermann, B., 2005. Modeling dissolved organic matter mobilization and immobilization in the root zone-effect of soil treatment on denitrification and $\mathrm{N}$ leaching. Department of Agricultural Science, The Royal Veterinary and Agricultural University 56pp.; Technical Report, online: 〈http://orgprints.org/5387/01/5387.pdf 〉.

Gjettermann, B., Styczen, M., Hansen, S., Borggaard, O.K., Hansen, H.C.B., 2007. Fractionation of dissolved organic matter and associated P during sorption to agricultural soil. Journal of Environmental Quality 36, 753-763.

Groenendijk, P., Kroes, J.G., 1999. Modelling the nitrogen and phosphorus leaching to groundwater and surface water; ANIMO 3.5. DLO Winanad Staring Centre, Wageningen, The Netherlands.

Guggenberger, G., Kaiser, K., 2003. Dissolved organic matter in soil: challenging the paradigm of sorptive preservation. Geoderma 113, 293-310.

Guggenberger, G., Zech, W., 1992. Retention of dissolved organic-carbon and sulphate in aggregated acid forest soils. Journal of Environmental Quality 21, 643-653.

Guggenberger, G., Zech, W., Schulten, H.R., 1994. Formation and mobilization pathways of dissolved organic-matter-evidence from chemical structural studies of organic-matter fractions in acid forest floor solutions. Organic Geochemistry 21, 51-66.

Hagedorn, F., Saurer, M., Blaser, P., 2004. A C-13 tracer study to identify the origin of dissolved organic carbon in forested mineral soils. European Journal of Soil Science 55, 91-100

Hansen, J.P., Vinther, F.P., 2001. Spatial variability of symbiotic N-2 fixation in grass-white clover pastures estimated by the N-15 isotope dilution method and the natural N-15 abundance method. Plant and Soil 230, 257-266.

Hansen, S., Jensen, H.E., Nielsen, N.E., Svendsen, H., 1990. DAISY-soil plant atmosphere system model. NPO-forskning fra Miljøstyrelsen No. A10 Miljøministeriet, Miljøstyrelsen.

Hansen, S., Jensen, H.E., Nielsen, N.E., Svendsen, H., 1991. Simulation of nitrogen dynamics and biomass production in winter-wheat using the Danish simulation-model DAISY. Fertilizer Research 27, 245-259.

Haynes, R.J., 1999. Size and activity of the soil microbial biomass under grass and arable management. Biology and Fertility of Soils 30, 210-216.

Hope, D., Billett, M.F., Cresser, M.S., 1994. A review of the export of carbon in river water-fluxes and processes. Environmental Pollution 84, 301-324.

Iversen, B.V., 2004. Soil hydraulic properties of Burrehøjvej field soil. Personal communication, Faculty of Agricultural Sciences, Institute of Agroecology and Environment, Research Centre Foulum, University of Aarhus. Unpublished data.

Jensen, L.S., Mueller, T., Bruun, S., Hansen, S., 2001. Application of the DAISY model for short- and long-term simulation of soil carbon and nitrogen dynamics. In: Shaffer, M.J., Ma, L., Hansen, S. (Eds.), Modeling Carbon and Nitrogen Dynamics for Soil Management. Lewis Publishers, Boca Raton, FL, pp. 483-509.

Kaiser, K., 2001. Dissolved organic phosphorus and sulphur as influenced by sorptive interactions with mineral subsoil horizons. European Journal of Soil Science 52 (3), 489-493.

Kaiser, K., Zech, W., 2000. Sorption of dissolved organic nitrogen by acid subsoil horizons and individual mineral phases. European Journal of Soil Science 51, 403-411.

Kaiser, K., Guggenberger, G., Zech, W., 1996. Sorption of DOM and DOM fractions to forest soils. Geoderma 74, 281-303.

Kaiser, K., Guggenberger, G., Haumaier, L., Zech, W., 1997. Dissolved organic matter sorption on subsoils and minerals studied by C-13-NMR and DRIFT spectroscopy. European Journal of Soil Science 48, 301-310. 
Kalbitz, K., Solinger, S., Park, J.H., Michalzik, B., Matzner, E., 2000. Controls on the dynamics of dissolved organic matter in soils: a review. Soil Science 165, 277-304.

Lofts, S., Simon, B.M., Tipping, E., Woof, C., 2001a. Modelling the solidsolution partitioning of organic matter in European forest soils. European Journal of Soil Science 52, 215-226.

Lofts, S., Woof, C., Tipping, E., Clarke, N., Mulder, J., 2001b. Modelling $\mathrm{pH}$ buffering and aluminium solubility in European forest soils. European Journal of Soil Science 52, 189-204.

McTiernan, K.B., Jarvis, S.C., Scholefield, D., Hayes, M.H.B., 2001. Dissolved organic carbon losses from grazed grasslands under different management regimes. Water Research 35, 2565-2569.

Mehra, O.P., Jackson, M.L., 1960. Iron oxide removal from soils and clays by dithionite-citrate systems buffered with sodium bicarbonate. In: Swineford, A. (Ed.), Clays and Clay Minerals. Proceedings of the Seventh National Conference on Clays and Clay Minerals: Conf. No. 7, Washington, DC, pp. 317-327.

Michalzik, B., Tipping, E., Mulder, J., Lancho, J.F.G., Matzner, E., Bryant, C.L., Clarke, N., Lofts, S., Esteban, M.A.V., 2003. Modelling the production and transport of dissolved organic carbon in forest soils. Biogeochemistry 66, 241-264.

Moore, T.R., Desouza, W., Koprivnjak, J.F., 1992. Controls on the sorption of dissolved organic-carbon by soils. Soil Science 154, $120-129$.

Neff, J.C., Asner, G.P., 2001. Dissolved organic carbon in terrestrial ecosystems: synthesis and a model. Ecosystems 4, 29-48.

Nodvin, S.C., Driscoll, C.T., Likens, G.E., 1986. Simple partitioning of anions and dissolved organic-carbon in a forest soil. Soil Science 142, 27-35.

Parton, W.J., Ojima, D.S., Cole, C.V., Schimel, D.S., 1994. A general model for soil organic matter dynamics: sensitivity to litter chemistry, texture and management. In: Bryant, R.B., Arnold, R.W. (Eds.), Quantitative Modeling of Soil Forming Processes. SSSA Special Publication 39, Madison, WI, USA, pp. 147-167.

Petersen, B.M., Berntsen, J., Hansen, S., Jensen, L.S., 2005. CN-SIM-a model for the turnover of soil organic matter. I: Long-term carbon and radiocarbon development. Soil Biology \& Biochemistry 37, 359-374.

Qualls, R.G., Haines, B.L., 1992. Biodegradability of dissolved organicmatter in forest throughfall, soil solution, and stream water. Soil Science Society of America Journal 56, 578-586.

Rey, A., Jarvis, P., 2006. Modelling the effect of temperature on carbon mineralization rates across a network of European forest sites (FORCAST). Global Change Biology 12, 1894-1908.

Römkens, P.F., Bril, J., Salomons, W., 1996. Interaction between Ca2+ and dissolved organic carbon: implications for metal mobilization. Applied Geochemistry 11, 109-115.

Schwertmann, U., 1964. Differzierung der eisenoxide des bodenss durch extraction mit ammoniumoxalat-lösung. Zeitschrift Pflanzenerenährung 105, 194-202.

Shaffer, M.J., Ma, L., Hansen, S., 2001. Modelling Carbon and Nitrogen Dynamics for Soil Management. Lewis Publisher, Boca Raton, FL, $651 \mathrm{pp}$.
Smith, P., Smith, J.U., Powlson, D.S., Arah, J.R.M., Chertov, O.G., Coleman, K., Franko, U., Frolking, S., Gunnewiek, H.K., Jenkinson, D.S., Jensen, L.S., Kelly, R.H., Li, C., Molina, J.A.E., Mueller, T., Parton, W.J., Thornley, J.H.M., Whitmore, A.P., 1997. A comparison of the performance of nine soil organic matter models using datasets from seven long-term experiments. Geoderma 81, 153-222.

Søegaard, K., Lund, P., Vinther, F.P., Petersen, S.O., Aaes, O., 2001. Afgræsning med malkekøer. Betydningen af kløveriblanding, BPVAAT-niveau i kraftfoder, slæt/afgræsning, ammoniakfordampning og N2 fiksering for udbytter og N-balancer. DJF rapport, Markbrug Nr. 51 (in Danish).

Soil Survey Staff, 1999. Keys to Soil Taxonomy. Pocahontas Press, Blacksburg VI.

Stepanauskas, R., Jorgensen, N.O.G., Eigaard, O.R., Zvikas, A., Tranvik, L.J., Leonardson, L., 2002. Summer inputs of riverine nutrients to the Baltic Sea: bioavailability and eutrophication relevance. Ecological Monographs 72, 579-597.

Tegen, I., Dorr, H., 1996. C-14 measurements of soil organic matter, soil $\mathrm{CO}_{2}$ and dissolved organic carbon (1987-1992). Radiocarbon 38, 247-251.

Tipping, E., Froberg, M., Berggren, D., Mulder, J., Bergkvist, B., 2005. DOC leaching from a coniferous forest floor: modeling a manipulation experiment. Journal of Plant Nutrition and Soil Science 168, 316-324.

Trumbore, S.E., Schiff, S.L., Aravena, R., Elgood, R., 1992. Sources and transformation of dissolved organic-carbon in the Harp lake forested catchment - the role of soils. Radiocarbon 34, 626-635.

Vaughan, R.E., Needelman, B.A., Kleinman, P.J.A., Allen, A.L., 2007. Spatial variation of soil phosphorus within a drainage ditch network. Journal of Environmental Quality 36, 1096-1104.

Vereecken, H., Jansen, E.J., Broeke Hackten, M.J.D., Swerts, M., Engelke, R., Fabrewiz, F., Hansen, S., 1991. Comparison of simulation results of five nitrogen models using different data sets. In: Commission of the European Communities (Ed.), Soil and Groundwater Research Report II: Nitrate in Soils: in the Framework of the 4. Environmental Research Programme, (1988-1990).

Vinther, F.P., Hansen, E.M., Eriksen, J., 2006. Leaching of soil carbon and nitrogen in sandy soils after cultivating grass-clover swards. Biology and Fertility of Soils 43, 12-19.

Wösten, J.H.M., Lilly, A., Nemes, A., Le Bas, C., 1998. Using existing soil data to derive hydraulic parameters for simulation models in 55 environmental studies and land use planning. Report 156, Agricultural Research Department, Wageningen, The Netherlands.

Zak, D.R., Grigal, D.F., Gleeson, S., Tilman, D., 1990. Carbon and nitrogen cycling during old-field succession - constraints on plant and microbial biomass. Biogeochemistry 11, 111-129.

Zsolnay, A., 1996. Dissolved humus in soil waters. In: Piccilo, A. (Ed.), Humic Substances in Terrestrial Ecosystems. Elsevier Science B.V., Amsterdam, pp. 171-223.

Zsolnay, A., Steindl, H., 1991. Geovariability and biodegradability of the water-extractable organic material in an agricultural soil. Soil Biology \& Biochemistry 23, 1077-1082. 